\title{
DESKRIPSI KARYA "DEK RANG MI" INTERPRETASI DEMOKRASI MINANGKABAU DALAM SEBUAH KARYA KOMPOSISI MUSIK
}

\author{
Oleh: \\ Auzy Madona Adoma \\ (Dosen FKIP Prodi Pendidikan Sendratasik Universitas PGRI Palembang)
}

\begin{abstract}
ABSTRAK
Demokrasi dalam masakat Minangkabau selalu berpedoman kepada ungkapan duduak surang basampik-sampik, duduak basamo balapang-lapang, duduak samo randah tagak samo tinggi. Dari ungkapan falsafah di atas pengkarya terjemahkan ke dalam sebuah garapan karya komposisi musik yang berjudul "Dek Rang Mi" yang diambil dari penggalan kata Demokrasi Rang Minangkabau.

Karya musik ini akan menyampaikan tiga buah penjelasan, pertama menjelaskan tentang makna duduak surang basampik-sampik maksudnya adalah proses bagaimana kita bisa serta menghargai pendapat orang lain. Kedua menjelaskan tentang makna duduak basamo balapang-lapang maksudnya adalah hidup berdemokrasi dalam masyarakat, menginterpretasikan kepentingan individu yang melebur menjadi kepentingan kelompok/masyarakat. Ketiga menjelaskan tentang makna duduak samo randah tagak samo tinggi maksudnya dalam musyawarah semua berhak dan bebas untuk mengeluarkan pendapat tanpa ada pengecualian. Proses penciptaannya melalui tahapan-tahapan, cara/metode yang digunakan meliputi eksplorasi, penafsiran individu, dan pembentukan. Dengan metode penciptaan tersebut, komposisi musik "Dek Rang Mi" disusun dan disajikan dalam tiga bentuk repertoar musik.
\end{abstract}

Kata kunci : : "Dek Rang Mi",Interpretasi Demokrasi.

\section{A. PENDAHULUAN}

\section{Demokrasi Minangkabau}

Demokrasi memiliki pengertian yang bermacam-macam, dapat diartikan sebagai kebebasan, dan ada juga yang mengartikannya sebagai beda pendapat. Begitu banyak pengertian demokrasi sehingga membuat manusia salah paham dalam melakukannya. Istilah demokrasi diutarakan di Athena pada tahun ke-5 SM. Negara tersebut dianggap sebagai contoh awal dari sebuah sistem yang berhubungan dengan sistem demokrasi modern. Kata demokrasi berasal dari dua kata, yaitu demos yang berarti rakyat, dan kratos/cratein yang berarti pemerintahan, sehingga dapat diartikan sebagai pemerintahan rakyat atau lebih, sering dikenal dengan pemerintahan dari rakyat, oleh rakyat, dan untuk rakyat.

$$
\text { Yerry } S \text { dalam bukunya }
$$

Minangkabau Dalam Persimpangan

Generasi menyebutkan "Menurut Samuel Hungtinton sistem politik sebagai demokratis, sejauh para pembuat keputusan kolektif yang paling kuat dalam sistem itu dipilih melalui pemilihan umum yang adil, jujur, dan semua orang dewasa mempunyai hak yang sama dalam hal pemberian suara. Namun dalam perkembangannya demokrasi tidak hanya sebagai pemerintahan dan 
sistem politik akan tetapi telah menjadi sikap hidup masyarakatnya (2007 : 25)."

Sistem demokrasi telah lama hidup dan berkembang pada masyarakat Minangkabau. Ini dibuktikan dengan Prasasti Batu Batikam di daerah Limo Kaum Kabupaten Tanah Datar. Dalam prasasti itu disebutkan bahwa setiap nagari atau wilayah di Minangkabau berhak memilih salah satu sistem pemerintahan, yaitu Lareh Bodi Caniago ataupun Lareh Koto Piliang sebagai sistem pemerintahan yang dipakai, dan juga boleh memakai kedua sistem pemerintahan tersebut. Hal ini membuktikan bahwa pemerintahan di Minangkabau diserahkan sepenuhnya kepada rakyat dan rakyat bebas memilih sistem pemerintahan yang sesuai dengan mereka (Kemal, 2009: 29). Bukan hanya itu, demokrasi juga telah menjadi sikap hidup masyarakat Minangkabau. Masyarakat Minangkabau berhak mengeluarkan pendapatnya masingmasing, perbedaan pendapat merupakan sesuatu yang wajar dalam masyarakat Minangkabau dalam tambo adat disebutkan Basilang kayu ditungku, mangkonyo api ka iduik (Navis, 1984: 20). Makna dari ungkapan tersebut adalah perbedaan pendapat merupakan suatu proses untuk mencari kata musyawarah serta mufakat, dan perbedaan pendapat sangat diperlukan untuk mencapai kehidupan yang lebih baik. Keadaan tersebut diibaratkan seperti kayu yang ditumpuk dengan tidak beraturan akan menghasilkan api dengan cepat.

Sistem demokrasi di Minangkabau tidak mengenal kata "sepakat untuk tidak se-mufakat" artinya setelah ada kata mufakat maka keputusan itu harus dilaksanakan oleh semua pihak. Keluar tetap utuh dan tetap satu, tanpa mempersoalkan proses keputusan itu diambil, dan juga dalam sistem demokrasi Minangkabau tidak mengenal pengambilan keputusan dengan suara terbanyak selalu di musyawarahkan untuk mencari kata sepakat dan mufakat (Kemal, 2009: 35) . Dalam masyarakat Minangkabau disebut dengan sikap serta watak Nan Sakato yang berarti sekata, sependapat, dan semufakat. Sikap ini dalam tambo adat Minangkabau disebutkan, Duduak surang basampiksampik, Duduak basamo balapang-lapang Duduak samo randah, Tagak samo tinggi.

Dt. Mangkuto mengatakan sebagai berikut:

"Ungkapan Duduak surang
basampik-sampik, basamo balapang-lapang, Duduak samo randah Tagak samo tinggi mengajarkan kepada masyarakat Minangkabau tentang hal berdemokrasi. Duduak surang basampik-sampik mengandung makna bahwa masyarakat harus bisa mengenal diri sendiri secara keseluruhan untuk menyelesaikan perbedaan yang terjadi akibat akal dan hawa nafsu. Selanjutnya yaitu Duduak basamo balapanglapang yang mengandung makna berdemokrasi dalam masyarakat. 
Duduak samo randah Tagak samo tinggi yang berarti demokrasi sesungguhnya di Minangkabau yaitu musyawarah dan mufakat serta selalu mempertimbangkan hubungan antarsesama, semua orang bisa memberikan ide, gagasan serta pemikirannya " (Hasil wawancara tanggal 26 Februari 2014).

Kenyataan yang terjadi pada masyarakat Minangkabau saat ini sangat berbeda dengan makna serta tujuan dari filsafah tambo adat di atas. Saat sekarang ini sikap bersosialisasi, demokrasi, serta kepedulian antar sesama sudah mulai pudar dalam kehidupan masyarakat Minangkabau. Berbagai perubahan yang sedang berlangsung di tengah kehidupan masyarakat telah membawa berbagai pengaruh pada pola budaya masyarakat Minangkabau. Perubahan itu telah membuat kabur nilai-nilai budaya masyarakat Minangkabau. Nilai-nilai lama masih dihormati akan tetapi tinggal pada tingkat wacana semata sehingga tidak bisa menyatu dalam kehidupan masyarakat Minangkabau.

Dalam menghadapi arus globalisasi saat ini, tidak semua masyarakat Minangkabau dapat beradaptasi dengan baik. Menurut Yerry S. dikatakan:

Setidaknya ada tiga syarat yang harus dipenuhi oleh suatu masyarakat untuk bisa hidup dan dapat beradaptasi dengan pola arus globalisasi. Pertama, masyarakat itu haruslah masyarakat yang reflektif, masyarakat yang dapat membebaskan diri dari tradisi, memandang tradisi dari luar secara sadar, dan menggunakannya secara sadar pula. Kedua, masyarakat tersebut juga harus mempunyai pengalaman hidup yang intensif di lingkungan yang plural dengan tingkat dinamika yang tinggi. Ketiga, masyarakat itu harus mempunyai kesediaan untuk tidak sekedar menerima perubahan dan keanekaan, melainkan juga untuk berinteraksi dan melakukan transaksi dengan serta juga mengakomodasi manusia, bendabenda, informasi, ideologi, yang berasal dari aneka ragam budaya.(2007: 80).

Sebagian masyarakat Minangkabau hampir tidak memenuhi ketentuan yang disebutkan di atas. Akibatnya saat sekarang ini sebagian besar masyarakat Minangkabau berada dalam suatu krisis identitas, krisis kepercayaan diri. Suatu masyarakat yang hilang pegangan, lupa akan istiadat budayanya sendiri.

Fenomena tersebut memberikan inspirasi kepada pengkarya untuk mengungkapkannya ke dalam sebuah garapan karya komposisi musik. Kebebasan telah diartikan salah oleh sebagian masyarakat Minangkabau sehingga terjadi kejadian-kejadian serta konflik-konflik seperti yang telah dijelaskan sebelumnya. Hal ini membuktikan bahwa ungkapan hidup duduak surang basampik-sampik, dudak basamo balapang-lapang, duduak samo randah, tagak samo tinggi sudah mulai 
pudar dalam tatanan hidup masyarakat Minangkabau.

\section{B. METODE PENELITIAN}

Peretti J. Pelto dan Gretel H. Pelto (1989: 14) mengemukakan bahwa tingkah laku kebudayaan sepatutnya dikaji dan dikategorikan mengikut pandangan orang yang dikaji itu sendiri, defenisi yang diberikan pelaku yang menjalani peristiwa itu. Inilah yang dimaksud dengan pendekatan fenomenologis yang amat penting diperhatikan dalam penelitian sosial masyarakat pada era globalosasi saat sekarang ini. Uraian tersebut diatas memberikan satu kejelasan bahwa dalam penelitian kualitatif tugas peneliti tidak hanya mencari data tetapi juga menganalisa data yang tersedia. Data-data yang didapat tidak saja dari hasil observasi atau pengamatan, tetapi juga berupa data-data yang bersumber dari buku-buku yang dipakai sebagai acuan juga dilakukan pendokumentasian dan wawancara.

\section{PEMBAHASAN DAN HASIL PENELITIAN}

\section{Deskripsi Karya}

Bagian pertama diawali dengan bunyi dari tempurung kelapa yang di gosokgosokkan ke lantai dimainkan oleh oleh 3 orang pemain, dan 4 pemain lagi mengadu tempurung kelapa dengan pola ritme yang tidak beraturan. Setelah itu dilanjutkan dengan permainan satu orang yang menjadi pengatur tempo dan pemain yang lain membuat pola sehingga terjadi pola ritme yang interlocking dari seluruh pemain. Selanjutnya permainan tempurung kelapa yang digosokkan ke lantai dengan pola ritme yang konstan dan beberapa orang pemain mengisi pola ritme tersebut dengan teknik bersahut-sahutan antar pemain. Setelah semua pemain memainkan pola ritme yang berbeda, mereka berkumpul di tengah-tengah tetap memainkan pola ritme, akan tetapi dengan dinamik yang semakin rendah atau mengecil, selanjutnya seluruh pemain melempar tempurung kelapa ke lantai secara bersamaan. Bersamaan dengan itu 4 orang pemain membuat pola ritme dari bambu yang dipakai di kaki menyerupai sandal dan memukul bambu dengan kayu. Pola ritme tersebut dimainkan dengan dinamika yang semakin keras, ditambah dengan bunyi bambu yang digosokkan ke lantai. Setelah itu dinamika permainan berangsur-angsur hilang dan hanya menyisakan satu orang pemain yang memainkan bambu dengan kayu.

Bagian kedua diawali dengan masuknya drown djiridu yang diselingi dengan bunyi triangle sebagai tanda masuknya permainan free kucapi oleh pemain, dengan notasi seperti di bawah ini : 


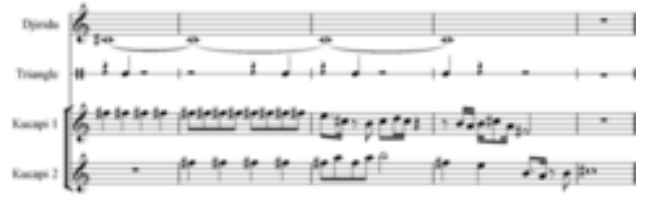

Dilanjutkan dengan free sampelong sekitar beberapa menit dengan iringan instrumen di atas, notasi untuk free sampelong adalah sebagai berikut :

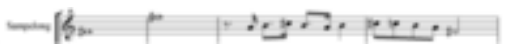

Permainan free sampelong ini juga terdapat free vokal yang mengikuti permainan dari melodi sampelong itu sendiri, dengan teks vokal :

Indak den sangko rigo rigo

Pipik sinanduang makan padi

indak den sangko cando iko

Pisau disaruang malukoi

Instrumen udu dan gong masuk secara perlahan dengan dinamika lunak yang bertujuan sebagai penghantar permainan cello dan vokal bersama oleh seluruh pemain, pengolahan vokal berupa call respon antara vokal pertama dengan vokal bersama, dengan notasi :

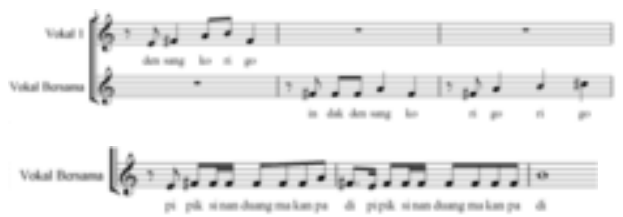

Keseluruhan permainan di atas diakhiri dengan rall oleh seluruh instrumen dan dilanjutkan dengan permainan mandolin sebagai pola melodi dasar yang mengiringi free vokal dan sampelong selanjutnya.
Penghabisan free vokal dan sampelong dilanjutkan dengan permainan seluruh instrumen yang terdiri dari beberapa permainan, yaitu :

Matrik tiga :

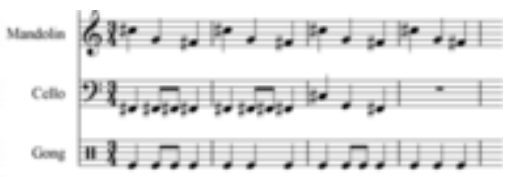

Interlocking dan call and respon :

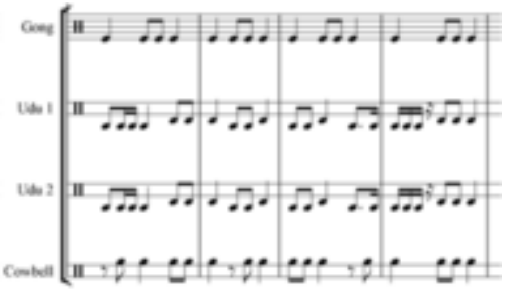

Permainan ini diakhiri rall oleh instrumen, udu sebagai hantaran masuk permainan melodi yang dimainkan oleh seluruh instrumen melodi, melodi tersebut seperti notasi berikut ini :

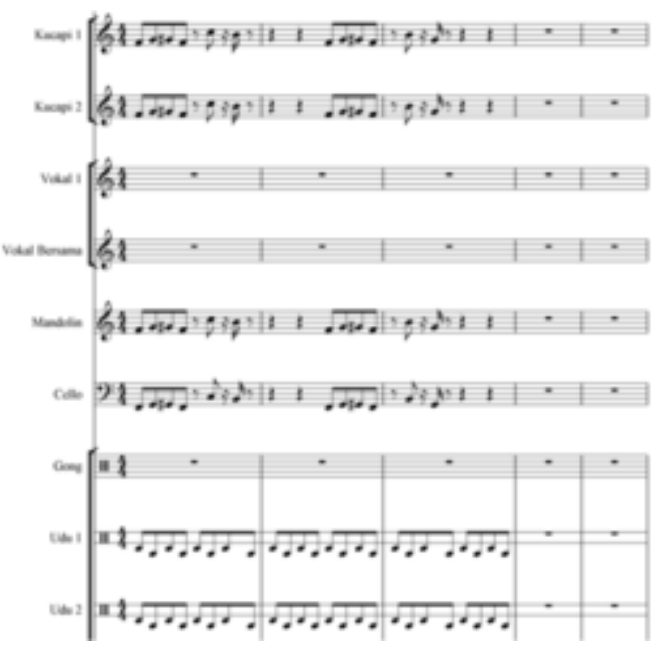

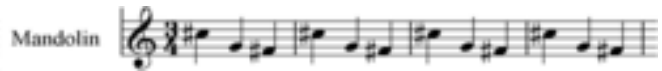


Dilanjutkan dengan permainan interlocking berikutnya antara instrumen perkusi dengan instrumen melodi :

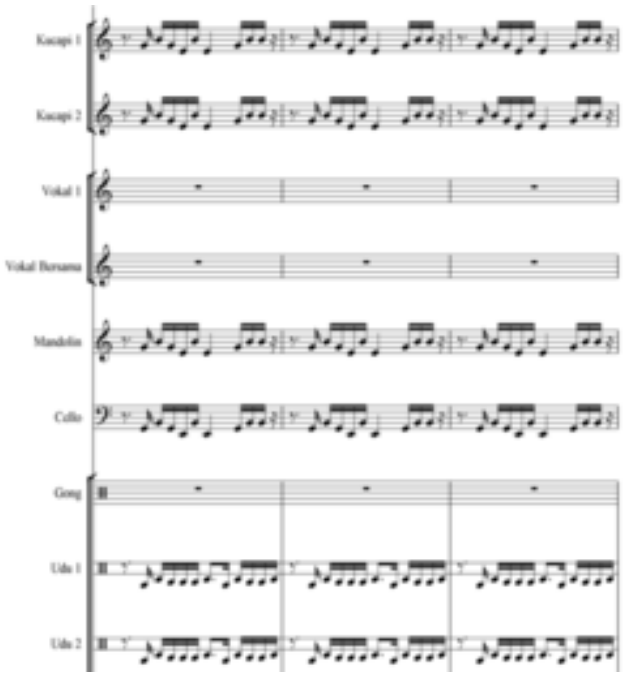

Selanjutnya permainan unisono

oleh seluruh instrumen melodi dengan isian oleh instrumen perkusi (udu)

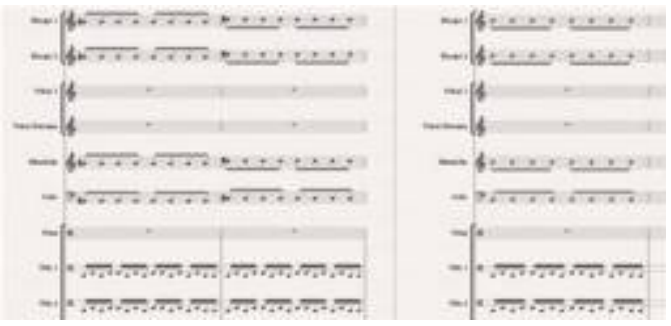

Keseluruhan permainan melodi di atas diakhiri dengan masuknya suling dan triangle sebagai penyambungan pada permainan melodi berikutnya

Permainan melodi ini merupakan permainan polymatrik yang dimainkan antara instrumen biola dengan cello sebagai melodi dasar dalam mengiringi instrumen kucapi dan mandolin dalam memainkan melodi lainnya.

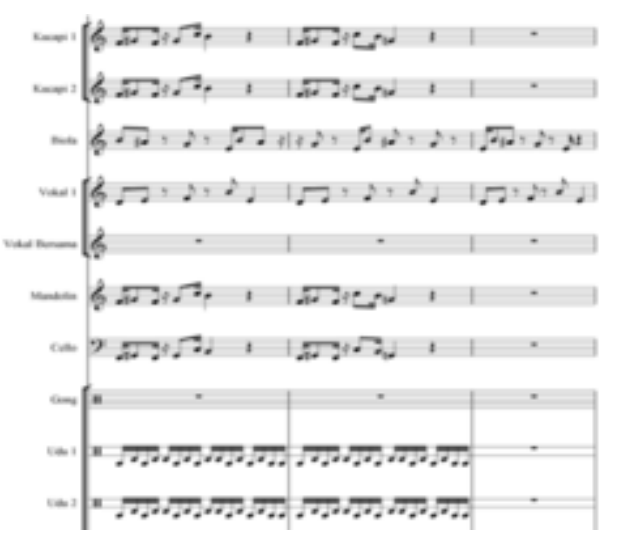

Bagian selanjutnya merupakan permainan melodi baru yang dibangun oleh permainan cello dan biola sebagai melodi awal, permainan ini diisi dengan call dan respon antara intrumen kucapi sampai adanya kode penutup oleh instrumen $u d u$.

Cello dan biola :

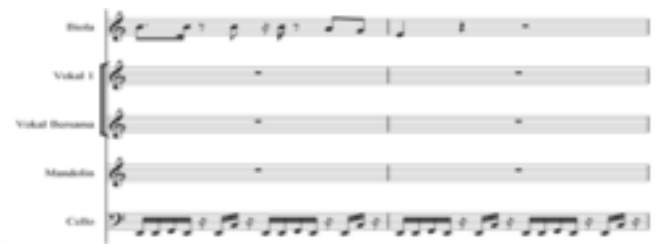

Udu dan kucapi :

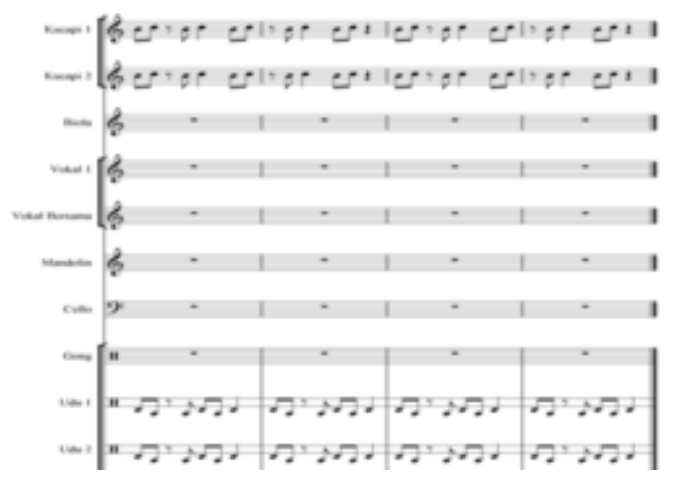

Free melodi mandolin masuk sebagai permainan dalam bagian selanjutnya hingga masuk triangle, free melodi cello, free melodi biola, dan free melodi sampelong dengan iringan melodi dasar oleh mandolin seperti notasi di bawah ini : 


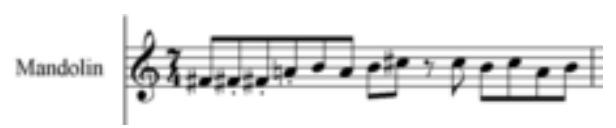

Bagian terakhir, udu dan kucapi masuk sebagai perkusi pengiring dalam permainan melodi di atas dan melodi akhir sama seperti melodi bagian awal.

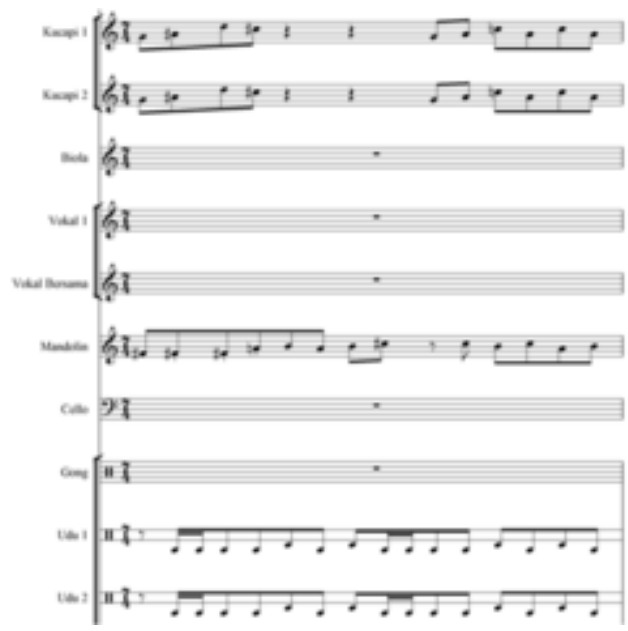

Melodi awal :

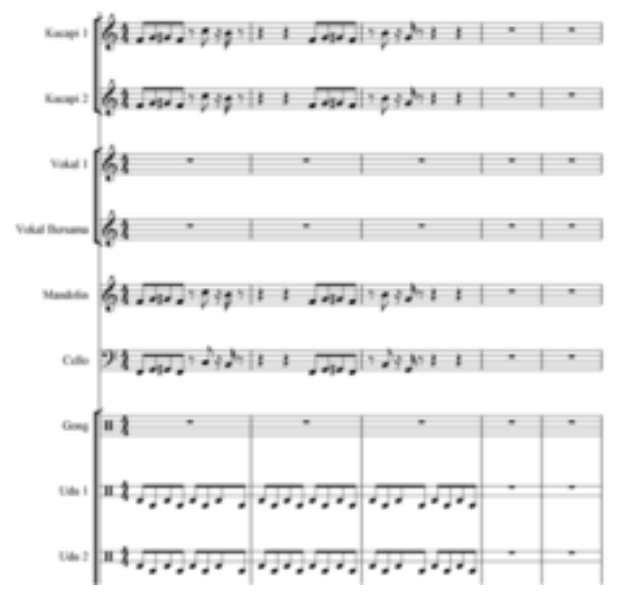

Bagian ketiga diawali dengan bunyi ganto yang diikuti oleh permainan snare drum sebagai kode untuk masuknya unisono seluruh instrumen, dengan unisono seperti notasi di bawah ini :
Unisono I :

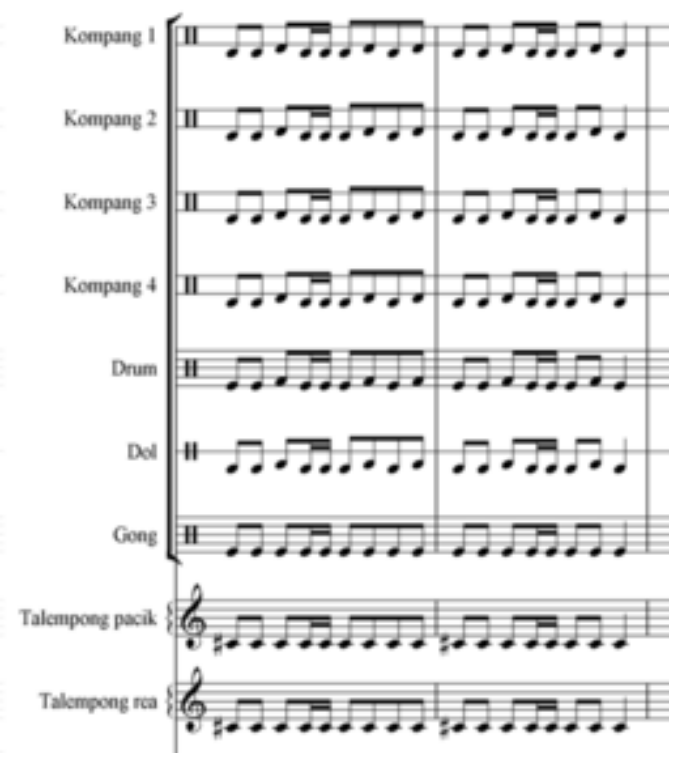

Unisono II :

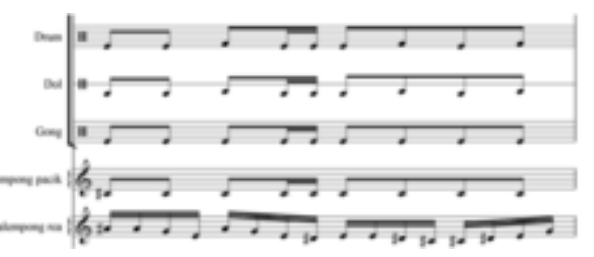

Dilanjutkan dengan permainan call respon antara instrumen kompang dengan talempong hingga masuk kembali unisono seperti di atas.

Call and Respon antara kompang dengan talempong :
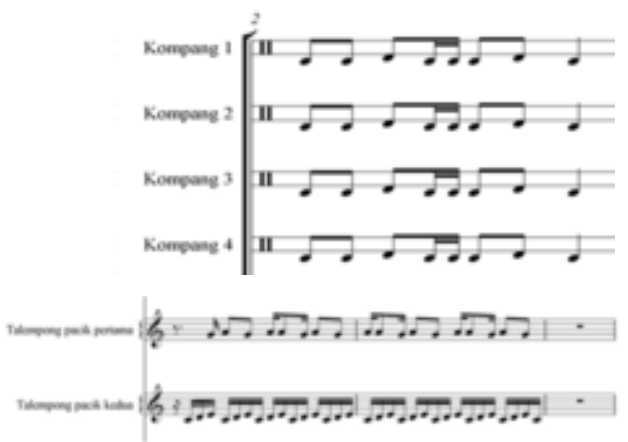

Unisono tersebut sebagai melodi dasar dalam permainan isian kompang sebelum masuk unisono berikutnya : 
Isian kompang :

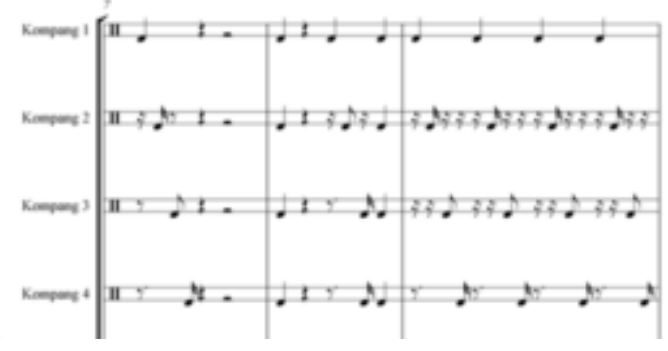

Berikutnya permainan bass dan saxophone yang bertujuan untuk masuknya penggarapan melodi pertama oleh instrumen beserta vokal :

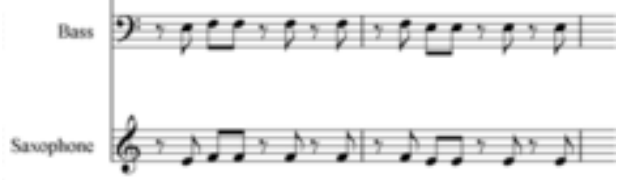

Dilanjutkan dengan permainan talempong sebagai isian dari perjalanan melodi di atas dengan sistem unisono antara talempong dengan perkusi lainnya.

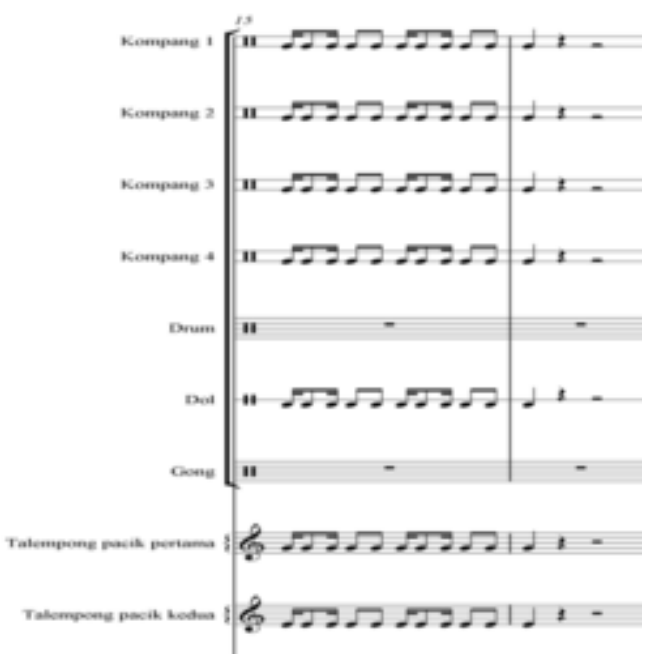

Masuk bagian berikutnya merupakan permainan talempong pacik yang penggarapan melodinya berpijak pada melodi talenpong unggan lagu pararakan kuntu frase kedua dengan permainan aksentuasi oleh instrumen lain (kompang, bass, drum, gong, dan dol).

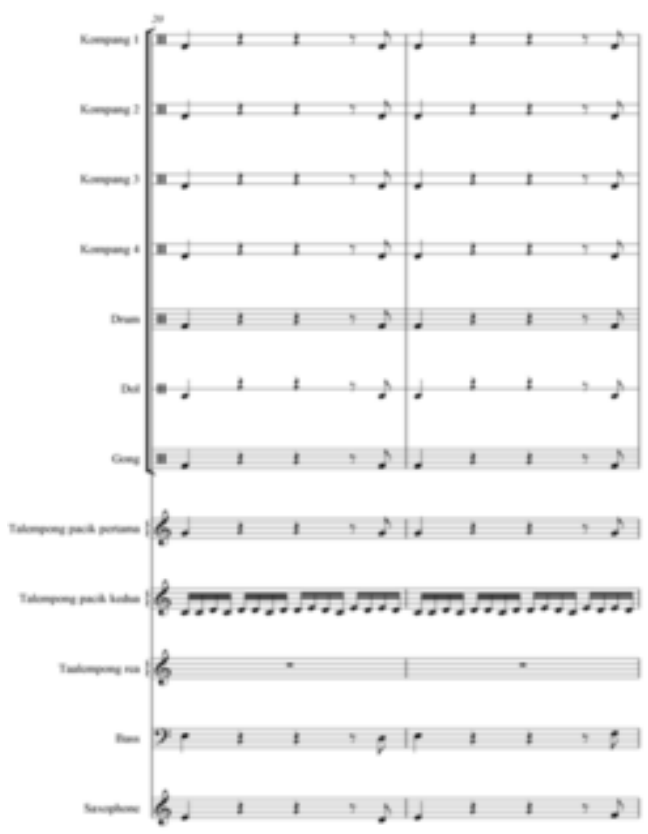

Permainan talempong pacik dengan isian aksentuasi ini diulang sebanyak dua kali pengulangan yang kemudian dilanjutkan dengan permainan kompang beserta perkusi lainnya.

Selanjutnya talempong pacik kembali masuk sebagai melodi dasar yang mengiringi permainan melodi oleh seluruh instrumen melodi. Permainan hocketing oleh kompang mengakhiri perjalanan melodi di atas. Keseluruhan talempong masuk dengan teknik permainan talempong pacik sebanyak beberapa kali pengulangan hingga seluruh instrumen kembali masuk dengan memainkan melodi yang berbeda dari melodi sebelumnya.

Vokal bersama hadir dalam bagian berikut ini yang terdiri dari beberapa pembagian teks vokal dalam 
penggarapannya, dengan teks vokal seperti di bawah ini :

\section{Iliaan lobuah padang ndoleh \\ Serak baserai abu sokam Indak den sangko lai ka lopeh \\ Tangan lah orek dek \\ manggonggam \\ Ontak tobuang den ontak tobuang \\ Nan den ontak jo puduang potai \\ Nda tatangguang indak \\ tatangguang \\ Den tadayo dek kuniang sempai}

Bagian penggarapan vokal ini diakhiri dengan unisono vokal dalam tempo yang cepat sebagai penyambungan pada permainan melodi bagian berikutnya.

Melodi pada bagian ini merupakan penggarapan melodi yang masih sama dengan bagian sebelumnya, yaitu talempong unggan lagu pararakan kuntu frase kedua, namun dalam bagian ini terdapat isian permainan hocketing antara satu kompang dengan kompang lainnya. Talempong pacik kembali sebagai melodi awal dalam bagian ini, yaitu bagian unisono yang sama pada awal bagian ketiga dengan lanjutan permainan oleh instrumen gong dalam bagian selanjutnya.

Gong sebagai instrumen pertama dalam permainan bagian ini, bagian ini merupakan permainan secara bergantian oleh talempong dan kompang yang diiringi oleh set drum dan dol. Setelah permainan tersebut, berikutnya adalah permainan melodi bass yang diiringi oleh instrumen dol, gong, set drum, kompang, serta talempong pacik.

Bagian selanjutnya merupakan bagian akhir dari keseluruhan bagian karya yang berjudul "Dek Rang Mi", yaitu permainan melodi oleh saxophone, talempong, dan bass yang diisi dengan interlocking kompang hingga unisono akhir yang sama pada awal bagian ketiga.

\section{Proses Berkarya}

Sudah merupakan keharusan bagi seorang pengkarya sebelum menampilkan karya terlebih dahulu melalui suatu proses, hal ini juga berlaku untuk pekerjaan lainnya. Justru itu hadirnya garapan karya komposisi musik "Dek Rang Mi" ini sedang melalui jalan berliku sebagai suatu proses, agar pada saat finalnya nanti dapat disajikan suatu garapan komposisi yang layak untuk dipertunjukan. Maka dari itu, bahwa dalam proses sangat diperlukan adanya latihan yang diprogramkan secara mantap, agar ide dapat dituangkan menjadi sebuah garapan komposisi music ( Sukerta, 2011 : 24). Bagi pengkarya proses menuangkan ide ke dalam sebuah komposisi musik bukanlah suatu hal yang mudah, maka dari itu pengorbanan, keberanian, dan ketelatenan pengkarya dituntut sekali dalam menerjemahkan dan mengaktualisasikan pesan dan aneka suasana, rasa, nilai yang terkandung dalam gagasan karya ini (Supanggah, $2005: 36$ ). 
Sebagaimana yang telah diuraikan pada bagian-bagian di atas sebelumnya garapan komposisi musik "Dek Rang Mi" berbentuk garapan baru. Adapun tahapantahapan kerja yang dilakukan dalam menggarap karya komposisi musik ini adalah :

\section{a. Tahap Eksplorasi}

Sebagai langkah awal proses penggarapan dalam tahap eksplorasi ini adalah menentukan tema garapan. Sebelum dituangkan kedalam bentuk garapan, dilakukan perenungan, memahami, merasakan, dan menafsirkan kembali apakah ide dan tema tersebut bisa diwujudkan dalam bentuk karya komposisi musik (Supanggah, 2005 : 40).

\section{b. Tahap improvisasi}

Sebagai tindak lanjut dari proses kerja pertama adalah tahap improvisasi, yaitu mencoba menafsirkan bagianperbagaian dari karya, dan memperkirakan alat musik apa yang bisa digunakan untuk mengaktualisasikan gagasan garap dalam komposisi musik, masing-masing bagian karya mempunyai karakter dan menggunakan alat yang berbeda-beda sehingga mampu melahirkan kesan, suasana dan rasa musikalitas yang diharapkan (Sukerta, 2011 : 38). Setelah mendapat gambaran yang jelas terhadap kesan dan suasana yang diinginkan, kemudian dituangkan kepada pendukung karya secara bertahap sampai terbentuknya suatu kerangka karya komposisi musik sebagaimana yang diharapkan.

\section{c. Tahap Pembentukan}

Setelah terbentuknya kerangka dan beberapa bagian-bagian karya komposisi musik, maka pada tahap pembentukan ini mulai merangkail menyambung bagianperbagian yang telah dituangkan kepada pendukung karya agar bentuk kasarnya terwujud, sehingga sudah dapat terlihat secara umum struktur atau susunan karya komposisi musik.

\section{DAFTAR PUSTAKA}

Hajizar, " Menguak Konsep Musikal Tiga Jenis Talempong Yang Langka Di Luhak Limo Puluah Koto Minangkabau". Laporan Penelitian. Padangpanjang : STSI Padangpanjang.,2002.

Kemal, Iskandar, "Pemerintahan Nagari Minangkabau dan Perkembangannya", Graha Ilmu, Yogyakarta, 2009.

Navis A.A, "Alam Takambang Jadi Guru", GrafitiPers, Jakarta, 1984. 
Sukerta, Pande Made, "Metode Penyusunan Karya Musik (Sebuah Alternatif)", ISI Press Solo, Solo, 2011.

Supanggah, Rahayu. "Garap: Salah Satu Konsep Pendekatan / Kajian Musik Nusantara", dalam Waridi, ed. Menimbang Pendekatan Pengkajian dan Penciptaan Musik Nusantara. Surakarta: Jurusan Karawitan \& STSI Press, Surakarta, 2005.

Yerri S. Putra, "Minangkabau di Persimpangan Generasi", Pusat Studi Humaniora dan Fakultas Sastra Universitas Andalas, 